\title{
Fine Needle Aspiration and Cytology in the Management of Head and Neck Masses in Osogbo, South Western Nigeria
}

\author{
Adedeji T01 ${ }^{1}$, Tobih JE${ }^{1 *}$, Olaofe $0^{2}$, Akinyemi HA ${ }^{2}$ and Sogebi $\mathbf{O A}^{3}$ \\ ${ }^{1}$ Department of ORL, Lautech Teaching Hospital, Nigeria \\ 2Department of Pathology, Lautech Teaching Hospital, Nigeria \\ ${ }^{3}$ Department of Surgery, Olabisi Onabanjo University, Nigeria
}

\section{Research Article}

Volume 3 Issue 1

Received Date: March 21, 2018

Published Date: April 05, 2018

DOI: $10.23880 /$ ooaj-16000165

*Corresponding author: James E Tobih, Department of Otorhinolaryngology Head and Neck Surgery, LAUTECH Teaching Hospital, Osogbo, Nigeria, Tel: 2348033857703; E-mail: pilgrimhouse2012@gmail.com

\section{Abstract}

Background: FNAC is a well-established technique for pre-operative evaluation of masses. This study aims to highlight the relevance of FNAC and to draw attention to its prospects and challenges in the management of head and neck masses. Methods: A retrospective descriptive study conducted between December 2005 and November 2013 at the ENT and pathology departments of LAUTECH Teaching Hospital, Osogbo, Nigeria.

Results: Total of 294 patients consisting of 113 males and 181 female with male: female ratio 1:1.6. Their ages ranged from 1-93 years (mean \pm SD of $38.25 \pm 1.98$ ) years. Age group $21-40$ years constituted the largest proportion 34.4\%. Cervical mass constituted the largest proportion of $37.4 \%$ followed by thyroid mass $23.5 \%$. Majority $35.2 \%$ were inflammatory/non specific lymphadenopathy followed by malignant masses $27.4 \%$. Among the males, $67 \%$ were benign and $23.3 \%$ were malignant while among the females, $54 \%$ were benign and $39.2 \%$ were malignant. There were preponderance of inflammatory/benign masses among the younger age groups while malignant masses were spread among the young adults, middle age and older age groups $(X 2=28.535, p=0.001)$. There is also no statistical significance in the distribution of head and neck masses between the two genders $(X 2=3.226, p=0.353)$.

Conclusion: FNAC is very relevant in the management of H\&N masses; the prospects for its use are equally high in our center. The challenges associated with the use of FNAC in our environment at this time were also addressed.

Keywords: Aspiration; Cytology; Head and Neck masses 


\section{Otolaryngology Open Access Journal}

Abbreviations: FNAC: Fine Needle Aspiration Cytology; PCR: Polymerase Chain Reaction

\section{Introduction}

Fine needle aspiration cytology (FNAC) is a wellestablished technique for pre-operative evaluation of masses. The technique is the most noninvasive, costeffective and efficient method of differentiating benign and malignant masses. Fine needle aspiration for cytological evaluation of a neck mass was first reported by Kun in 1847 [1]. In 1930s, Memorial Sloan Kettering rediscovered the utility of needle biopsy of head and neck masses [1]. However, the procedure did not gain wide acceptance in medicine at that time mainly due to its frequently-associated morbidities as a result of wide bore needle employed at the time and with its tendency to seeding of malignant cells [1]. However, a resurgence of FNAC occurred in the 1950s following modification of the needle employed in aspiration of the masses/ swellings. Since then, FNAC of solitary masses has become a wellaccepted, safe, and cost-effective procedure in the diagnosis of solitary masses.

In Nigeria, FNAC is gaining an increasing recognition in the screening and diagnoses of a variety of inflammatory and neoplastic conditions [2,3]. The procedure (FNAC) is a simple and sensitive alternative to open surgical biopsy $[3,4]$. Few published studies have shown that the procedure can be easily adapted to address the peculiar healthcare challenges in developing countries including Nigeria [5,6]. In most developed and some developing countries like India, Malaysia and South Africa, FNAC not only enjoys widespread acceptability but it has become a flourishing diagnostic and/ or therapeutic tool in such countries [7]. Some of the benefits of FNAC include cost effectiveness, rapid reporting and bedside diagnosis, minimal physical and psychological discomfort, elimination of a two-stage procedure for diagnosis and treatment, active participation of the patient in treatment planning, and serving as a therapeutic procedure for evacuation of cystic lesions [6].

Previous researchers in Nigeria had also demonstrated high sensitivity and specificity of FNAC with a diagnostic accuracy ranging between 79.0 and $96.1 \%$ [3]. This has also been found to have contributed into its increasing popularity and utilization in preoperative diagnosis. However, there are few reports on head and neck FNAC in the published studies in Nigeria $[3,8,9]$. This study aims to highlight the relevance of FNAC and to draw attention to its prospects and challenges in the management of head and neck masses.

\section{Materials and Methods}

This study was a retrospective descriptive study of patients with head and neck masses who had FNAC done between December 2005 and November 2013 at the ENT and pathology departments of LAUTECH Teaching Hospital, Osogbo, Nigeria. Data of all patients with head and neck masses were retrieved for the study. Information was obtained from the clinical charts of patients which included socio-demographics, duration of neck mass before presentation at the hospital, FNAC findings/diagnosis and treatment modalities.

The procedure for FNAC employed in the hospital entailed aspiration using a fine bore needle and a $20 \mathrm{ml}$ syringe. The aspirates were smeared on a clean slide and macroscopically examined for adequacy. Some of the smears from each mass were fixed in alcohol and stained with Haematoxylin-Eosin stains and Papanicolau stain. Other smears were air dried and stained with Giemsa. The stained slides were then examined using a binocular microscope and diagnosis based on standard criteria.

Patients' information including the clinical parameters was recorded. Data of patients with incomplete information and those that were lost to follow-up were excluded from the study. The data were entered into a spreadsheet and presented in a descriptive form as proportions, means and standard deviations as appropriate, in tabular and graphic forms. A statistical analysis was performed using statistical package for social sciences (SPSS) version 16 (Chicago, IL).

\section{Results}

Data of 294 patients with complete records were analyzed. This represents $60.6 \%$ of the head and Neck masses seen in the ENT Department during the period of study. There were 113 (38.4\%) males and 181 (61.6\%) female with male: female ratio 1:1.6. The age of the patients ranged from 1 year to 93 years with a mean \pm SD of $38.25 \pm 1.98$ years. Age group $21-40$ years constituted the largest proportion 101(34.4\%) followed by age group 41 - 60 years $84(28.6 \%)$. Table 1 shows the age and gender distributions of the patients. 


\section{Otolaryngology Open Access Journal}

\begin{tabular}{|c|c|c|c|}
\hline \multirow{2}{*}{$\begin{array}{c}\text { Age group } \\
\text { (Years) }\end{array}$} & \multicolumn{2}{|c|}{ Gender } & \multirow{2}{*}{ Total } \\
\cline { 2 - 3 } & Male & Female & \\
\hline $1-20$ & 33 & 30 & 63 \\
\hline $21-40$ & 37 & 64 & 101 \\
\hline $41-60$ & 29 & 55 & 84 \\
\hline$\geq 61$ & 14 & 30 & 44 \\
\hline \multirow{2}{*}{ Mean \pm SD } & $34.9558 \pm$ & $40.2001 \pm$ & \\
& 2.001 yrs. & 1.9463 yrs & \\
\hline
\end{tabular}

Table 1: Age and gender distribution of the patients

Site distribution shows that cervical mass/lymph node constituted the largest proportion of $37.4 \%$ in 110 patients followed by thyroid mass $(23.5 \%)$ in 69 patients, jaw mass $(10.9 \%)$ in 32 patients, parotid swelling was $(6.5 \%)$ in 19 patients and others (randomly spread in cheek, oral cavity, scalp and face) 64 (21.8\%). The spectrum of cytological diagnosis is shown in Figure 1. Inflammatory/ non specific lymphadenopathy constituted the largest proportion $81 / 230 \quad(35.2 \%)$ followed by malignant masses $63(27.4 \%)$ and benign masses 55 $(23.9 \%)$ in that order. Among the males, 58/86 (67\%) were benign and 20/86 (23.3\%) were malignant, while lymphoma and suspicious masses were $7 \%$ and $2.3 \%$ respectively. Among the females 77/143 (54\%) were benign masses, 56/143 (39.2\%) were malignant masses, lymphoma and suspicious masses were $4.2 \%$ and $2.8 \%$ respectively. The difference in the cervical mass types between the sexes was not statistically significant (X2 = $14.232, \mathrm{p}<0.05$ ).

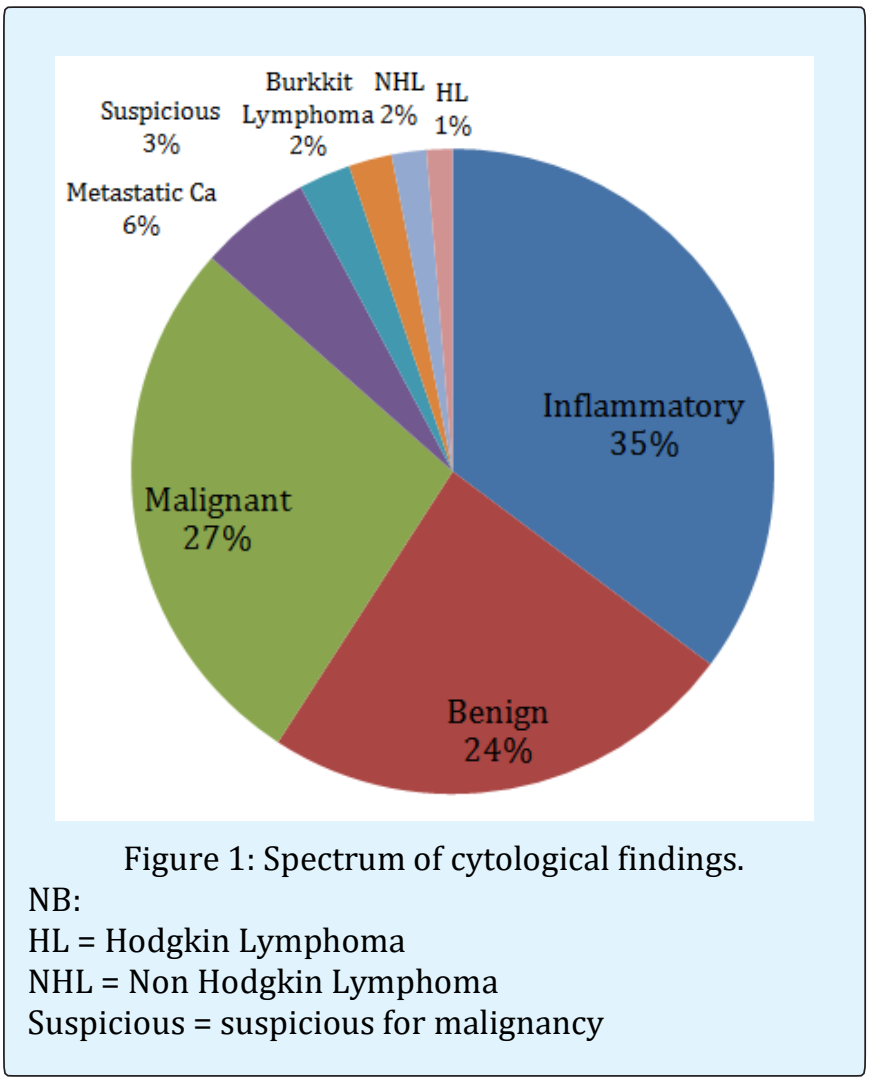

Cytological distribution among different age groups revealed preponderance of inflammatory/benign masses among the younger age groups while malignant masses were spread among the young adults, middle age and older age groups $(\mathrm{X} 2=28.535, \mathrm{p}=0.001)$. Table 2 shows cytological distribution among different age groups.

\begin{tabular}{|c|c|c|c|c|c|}
\hline \multirow{2}{*}{ Cytology } & \multicolumn{4}{|c|}{ Age of patients (years) } & \multirow{2}{*}{ Total } \\
\cline { 2 - 5 } Inflammatory & $1-20$ & $21-40$ & $41-60$ & $>60$ & \multirow{2}{*}{$81(35.4 \%)$} \\
\hline Benign & $9(51 \%)$ & $22(28.9 \%)$ & $22(33.8 \%)$ & $11(29.7 \%)$ & $85(24.0 \%)$ \\
\hline Lymphoma & $8(15.7 \%)$ & $3(3.9 \%)$ & $1(1.5 \%)$ & $0(0 \%)$ & $12(5.2 \%)$ \\
\hline Malignant & $7(13.7 \%)$ & $30(39.5 \%)$ & $23(35.4 \%)$ & $15(40.5 \%)$ & $75(32.8 \%)$ \\
\hline Suspicious & $1(2.0 \%)$ & $1(1.3 \%)$ & $1(1.5 \%)$ & $3(8.1 \%)$ & $6(2.6 \%)$ \\
\hline Total & $51(100 \%)$ & $76(100 \%)$ & $65(100 \%)$ & $37(100 \%)$ & $229(100 \%)$ \\
\hline
\end{tabular}

Table 2: Cytological distribution among different age groups 


\section{Otolaryngology Open Access Journal}

Among the cervical lymph node masses, 33\% were neoplastic, among the parotid masses, $35.3 \%$ were neoplastic while $18.5 \%$ of thyroid masses were neoplastic. Preponderance of lymphoma 6/12 (50\%) were found in the cervical masses while the remaining $50 \%$ were distributed / spread in the cheek, oral cavity, scalp and face. This was not statistically significant (X2 = 14.232, $\mathrm{p}=0.114$ ). Table 3 shows the cytological diagnosis among different head and neck masses. There is also no statistical significance in the distribution of head and neck masses between the two genders $(\mathrm{X} 2=3.226, \mathrm{p}$ $=0.353$ ).

\begin{tabular}{|c|c|c|c|c|}
\hline \multirow{2}{*}{ Variables } & \multicolumn{2}{|c|}{ Cytology } & \multirow{2}{*}{ Total } \\
\cline { 2 - 4 } Types of H\&N masses & Benign & Malignant & Suspicious & \\
\hline Cervical lymphadenopathy & $54(53.5 \%)$ & $44(43.6 \%)$ & $3(2.9 \%)$ & $101(100 \%)$ \\
\hline Thyroid mass & $40(74.1 \%)$ & $11(20.4 \%)$ & $3(5.6 \%)$ & $54(100 \%)$ \\
\hline Parotid mass & $11(64.7 \%)$ & $6(35.3 \%)$ & 0 & $17(100 \%)$ \\
\hline Others & $31(54.4 \%)$ & $26(45.6 \%)$ & 0 & $57(100 \%)$ \\
\hline Total & $136(59.4 \%)$ & $87(38 \%)$ & $6(2.6 \%)$ & $229(100)$ \\
\hline Gender & & & & \\
\hline Male & $53(61.6 \%)$ & $31(36.0 \%)$ & $2(2.4 \%)$ & $86(100 \%)$ \\
\hline Female & $83(58.0 \%)$ & $56(39.2 \%)$ & $4(2.8 \%)$ & $143(100 \%)$ \\
\hline Total & $136(59.4 \%)$ & $87(38 \%)$ & $6(2.6 \%)$ & $229(100)$ \\
\hline
\end{tabular}

Table 3: Cytological findings among different head and neck organs $\&$ between the two genders

\section{Discussion}

Over $60 \%$ of the head and Neck masses seen in the ENT Department which were sent for FNAC confirm its relevance in making diagnoses of $\mathrm{H} \& \mathrm{~N}$ masses. There is increasing evidence that FNAC practice in Nigeria is undergoing rapid growth due to the enthusiastic support and progressive interest of the pathologists. $[3,10,11]$. The increasing acceptability of FNAC has been demonstrated to be due to its cost saving and its accuracy [3]. For uniformity, consistency and accuracy of results, the pathologist preferentially performs the aspiration of the masses in our center. This was the case in most centers in Nigeria in contrast to the practice in the United States and United Kingdom where majority of aspirations were performed essentially by surgeons and radiologists $[2,4]$. The aspirator is a significant factor in the success of FNAC in any given situation, and there are superior arguments in favor of pathologists as is the practice in Nigeria where pathologists perform the aspirations themselves $[3,4]$. This might be due to the pool of patients that pass through them which give them ample opportunity to gain experience in contrast to situations where fine needle aspirations are performed on individual specialist bases.

In the present study, we found that spectrum of neck masses cut across all the age groups. Arul, et al. [12] reported that lesions arising in cervical lymph nodes can be found in patients ranging from early to advanced age. Similar findings were reported by other published studies $[13,14]$. This connotes that age is not a barrier to the conduct of FNAC of any suspicious head and neck masses. In most children selected for open biopsy, reactive hyperplasia and other inflammatory causes are far more common as a final diagnosis than malignancy, thus performing FNAC in such cases will serve as a guide to avoid unnecessary open biopsy [15]. Thus FNAC remains a relevant procedure as a diagnostic procedure in all age groups.

Although, detailed history and thorough physical evaluation are invaluable in the assessment of patients with head and neck masses, clinical evaluation of a solitary neck mass can sometimes be difficult because of the extensive differential diagnoses. A fine-needle aspiration of the neck mass becomes very relevant especially if physical examination does not clarify the neck mass. Decisions regarding modality of treatment using surgery, radiation, or chemotherapy of neck masses, should be deferred until the FNAC result of the mass is obtained.

FNAC apart from its benefits as regards cost and time saving, the procedure does not interfere with further treatment modality. Birchall, et al. [16] reported that $60 \%$ of patients undergoing excision biopsy of masses experienced complications like compromise of later 


\section{Otolaryngology Open Access Journal}

tumor resection, the necessity for excision of extra skin and adjacent soft tissue, and local recurrence in the neck wound after surgery in relation to the previous biopsy. FNAC under the appropriate conditions complements clinical diagnosis. However FNAC should not be considered a substitute for a thorough history and physical examination.

The present study revealed preponderance of females with neck masses (61.8\%). This finding was in tandem with reports of findings from other previous researchers $[12,17]$. The reasons for female preponderance were however not known. Ahmad, et al. [18] reported male preponderance in their study although the drawback in their findings was its small sample size compared to other studies. Consistency exists between ours and findings from other workers as regards the distribution of masses among organs in the head and neck region with cervical lymphadenopathy followed by thyroid masses as the predominant neck masses $[17,19,20]$.

In the current study, there is preponderance (59.0\%) of benign lesion (inflammatory and benign neck swellings) while malignant (including suspicious for malignancy) accounted for $41.0 \%$. The proportion of benign lesions in our study is less when compared with those found in most of the previous studies especially in developing countries. Arul, et al. [12] reported 81.75 prevalence of benign lesion. Their observation was similar to those reported by other workers in India and Nepal [20-22]. Studies from the western world however reported higher prevalence of malignant neck masses. Cheng, et al. [23] in New Zealand reported $50 \%$ prevalence of malignant cases among 187 patients. Schelkun, et al. [24] in Chicago, USA, reported a prevalence of $40 \%$ of malignant variety of neck masses while Schwarz, et al. [25] in Columbia, Canada, reported a prevalence of $48 \%$ of malignant variety of neck masses. The findings from our study and those stated above show an epidemiological variation not only between the developed and developing countries, but also among developing countries.

Our findings of nonspecific lymphadenitis as the most common neck masses in the present study was similar to the report of el-Hag, et al. [26] in Saudi Arabia where reactive/non-specific lymphadenitis constituted the most common cause of neck masses accounting for 33\% among 225 patients. Most studies done in developing countries have consistently shown tuberculosis and reactive/nonspecific lymphadenitis to be the more common cause of neck masses. Arul [18] in India and Adhikari, et al. [20] in Nepal reported tuberculosis lymphadenitis as the most common pathology responsible for neck masses. The TB lymphadenitis is a consequence of high burden of pulmonary TB in many developing countries. TB bacilli usually gains entrance into cervical lymph nodes via the lymphoid tissues especially from Waldeyer's ring (tonsils or adenoids). An author had opined that while infections like TB are more commonly found in developing countries, malignancies are more common cause of neck swellings in developed countries [19].

The findings from our study were at variance with the report from most published studies as there was no case of tuberculosis lymphadenitis found in the study. A recent study from South-Eastern Nigeria reported a remarkable decline in the prevalence of cervical TB lymphadenitis. Most of the TB lymphadenitis patients in their study had associated HIV/AIDS disease which was a reversal of trends between pre and post HIV/ AIDS era [27]. This might also be a contributing factor to our findings as there was no record of patient with full blown AIDS among our cases. Another factor that might have contributed to the absence of TB lymphadenitis in our study may be related to the fact that instrument like polymerase chain reaction (PCR) which has better yield at detecting TB than most other instrument is not available in our center at present. Therefore, there is an urgent need for such modern diagnostic facility in our locality to facilitate better diagnosis and effective patient care/treatment. We only requested for $\mathrm{AFB}$ in suspected cases.

Another notable finding from the present study is the apparent rising cases of malignancy among young adults (21-40 years of age).This trend had been reported by authors from developing countries most especially in Africa [28-30]. Gilyoma, et al. [31] in East Africa reported highest prevalence of head and neck tumours in the fourth decade of life. The findings of most studies showed that head and neck cancers seem to affect Africans at younger ages than Caucasians [28,29]. Although reasons for higher percentage of occurrence in younger age group among Africans are not clear, associated factors may include genetics, poverty and behavioral practices. Shorter life expectancy in Africans compared with Caucasians, and earlier exposure to risk factors for carcinogenesis has also been speculated [31].

Our finding (based on the small proportion of malignancy detected in thyroid masses) corroborated the previous assertion that, the use of FNAC for thyroid masses could be selective and be based only on clinical suspicion [32]. Burnand, et al. [33] opined that FNAC is helpful for the diagnosis of salivary gland tumours where 


\section{Otolaryngology Open Access Journal}

it can differentiate between a malignant and a benign tumour with over $90 \%$ accuracy. FNAC is particularly helpful in the work-up of cervical masses and nodules because biopsy of cervical adenopathy should be avoided unless all other diagnostic modalities have failed to establish a diagnosis [34]. Although FNAC does not give the same architectural detail as histology, it can provide cells from the entire lesion as many passes through the lesion can be made while aspirating and in fact all neck masses should undergo FNAC and culture if necessary [33]. The reliability of FNAC can be improved upon by the combination of ultrasound guidance, capillary collection with no-aspiration technique, and on-site review of slides $[32,35]$.

There are limitations associated with this study; hospital - based nature of the study may not completely reflect the burden of head and neck tumours in the communities. Incomplete and loss of information are rampant in retrospective studies such as this; for instance, the total number of patients that had FNAC performed in Pathology department could not be ascertained. Lack of comparative analysis between FNAC findings and histological diagnosis is also a limitation; however previous studies in our environment had reported a diagnostic accuracy of $94.2-95.0 \%$ and confirmed FNAC is both specific and sensitive in detecting malignancy [34].

\section{Conclusion}

This study found that FNAC is very relevant in the management of H\&N masses, and the prospects for its use are equally high in our center. The challenges associated with the use of FNAC in our environment at this time have also been addressed. It is recommended that FNAC should be the initial investigation for patients with head and neck masses/diseases except for thyroid mass where it should be patient-selective. We encourage physicians/clinicians especially head and neck surgeons to embrace this investigative procedure in the management of head and neck masses.

\section{References}

1. Ryd W, Hagmar B, Eriksson O (1983) Local tumour cell seeding by fine-needle aspiration biopsy. A semiquantitative study. Acta Pathol Microbiol Immunol Scand A 91(1): 17-21.

2. Malami SA, Iliyasu Y (2008) Fine Needle Aspiration Cytology in Nigeria. Acta Cytol 52(4): 400-403.
3. Malami SA, Ochicha O (2011) A review of the utilization of fine needle aspiration in clinical practice and research in Nigeria. Cytojournal 8: 12.

4. Gupta DK, Mooney EE, Layfield LJ (2000) Fine-needle aspiration cytology: A survey of current utilization in relationship to hospital size, surgical pathology volume and institution type. Diagn Cytopathol 23(1): 59-65.

5. Mohammed AZ, Edino ST, Ochicha O, Alhassan SU (2005) Value of fine needle aspiration in preoperative diagnosis of palpable breast lumps in resource-poor countries: A Nigerian experience. Ann Afr Med 4(1): 19-22.

6. Thomas JO, Amanguno AU, Adeyi OA, Adesina AO (1999) Fine needle aspiration (FNA) in the management of palpable masses in Ibadan: Impact on the cost of care. Cytopathology 10(3): 206-210.

7. Knight BK (1996) Fine needle aspiration cytology in South Africa. Cyto Paths 40: 4-5.

8. Prathima S, Suresh TN, Harendra ML, Kumar, Krishnappa J (2014) Fine Needle Aspiration Cytology in Pediatric Age Group with Special Reference to Pediatric Tumors: A Retrospective Study Evaluating Its Diagnostic Role and Efficacy. Ann Med Health Sci Res 4(1): 44-47.

9. Rapkiewicz A, Thuy Le B, Simsir A, Cangiarella J, Levine P (2007) Spectrum of head and neck lesions diagnosed by fine-needle aspiration cytology in the pediatric population. Cancer 111(4): 242-251.

10. Bhursnamath SR, Afolayan EA, Bhursnamath B (1986) Fine needle aspiration biopsy cytology (FNAB) in diagnosis of tumours. West Afr J Med 5: 41-47.

11. Malami SA, Ojo BA (2006) Experience with Fine Needle Aspiration (FNA) Cytology for Diagnostic Work-up in Children in Nigeria. J Cytol 23: 191-195.

12. Arul P, Masilamani S, Akshatha C (2016) Diagnostic Efficacy of the Fine - Needle Aspiration Cytology in the Evaluation of Cervical Lymphadenopathy. Journal of the Scientific Society 43(3): 117-121.

13. Hafez NH, Tahoun NS (2011) Reliability of fine needle aspiration cytology (FNAC) as a diagnostic tool in cases of cervical lymphadenopathy. J Egypt Natl Canc Inst 2011(23): 105-114. 


\section{Otolaryngology Open Access Journal}

14. Babu GS, Ramesh G, Kashyap B, Suneela S, Hiremath SS, et al. (2014) Cyto histopathological evaluation of the cervical lymphnodes by fine needle aspiration cytology. J Cranio Max Dis 3: 101-105.

15. Locke R, Comfort R, Kubba H (2014) when does an enlarged cervical lymph node in a child need excision? A systematic review. Int J Pediatr Otorhinolaryngol 78(3): 393-401.

16. Birchall MA, Stafford ND, Walsh-Waring GP (1991) Malignant neck lumps: a measured approach. Ann R Coll Surg Engl 73(2): 91-95.

17. O'Donnell ME, Salem A, Badger SA, Sharif MA, Kamalapurkar D (2009) Fine needle aspiration at a Regional Head and Neck Clinic: A clinically beneficial and cost-effective service. Cytopathology 20(2): 8186.

18. Poorey VK, Tyagi P (2014) Accuracy of fine needle aspiration cytology in the head and neck masses. Indian J Otolaryngol Head Neck Surg 66(2): 182-186.

19. Ahmad T, Naeem M, Ahmad S, Samad A, Nasir A (2008) Fine Needle Aspiration Cytology (FNAC) And Neck Swellings In The Surgical Outpatient. J Ayub Med Coll Abbottabad 20(3) 30-32.

20. Adhikari RC, Shrestha HK, Sharma SK (2014) Fine needle aspiration cytology of neck masses in a hospital. J Nepal Health Res Counc 12(27): 104-108.

21. Biswas G, Das A, Haldar D, Mukherjee A, Dutta S, et al. (2013) Clinico pathological correlates of cervical lymphadenopathy: A hospital based study. Indian J Otolaryngol Head Neck Surg 65(1): 42-47.

22. Bhuyan MA, Fakir MA, Tofazzal Hossain AB, Zahurul Huq AH, Gupta S (2008) Role of Fine needle aspiration cytology in the diagnosis of cervical lymphadenopathy. Bangladesh J of Otorhinolaryngology 14(2): 63-65.

23. Cheng AT, Dorman B (1992) Fine needle aspiration cytology: the Auckland experience. Aust N Z J Surg 62(5): 368-372.

24. Schelkun PM, Grundy WG (1991) Fine-needle aspiration biopsy of head and neck lesions. J Oral Maxillofac Surg 49: 262-267.
25. Schwarz R, Chan NH, MacFarlane JK (1990) Fine needle aspiration cytology in the evaluation of head and neck masses. Am J Surg 159(5): 482-485.

26. el Hag IA, Chiedozi LC, al Reyees FA, Kollur SM (2003) Fine needle aspiration cytology of head and neck masses. Seven years' experience in a secondary care hospital. Acta Cytol 47(3): 387-392.

27. Ukekwe FI, Olusina DB, Banjo AAF, Akande OR, Nzegwu MA, et al. (2016) Tuberculosis Lymphadenitis in South-Eastern Nigeria; A 15 Years Histopathology Review (2000-2014). Ann Med Health Sci Res 6(1): 44-49.

28. Lilly-Tariah OB, Somefun AO, Adeyemo WL (2009) Current evidence on the burden of head and neck cancers in Nigeria. Head Neck Oncol 1: 1-14.

29. Ologe FE, Adeniji KA, Segun-Busari S (2005) Clinicopathological study of head and neck cancers in Ilorin, Nigeria. Trop Doct 35(1): 2-4.

30. Onyango JF, Macharia IM (2006) Delays in diagnosis, referral and management of head and neck cancer presenting at Kenyatta National Hospital, Nairobi. East Afr Med J 83(4): 85-91.

31. Gilyoma JM, Rambau PF, Masalu N, Kayange NM, Chalya PL (2015) Head and neck cancers: a clinicopathological profile and management challenges in a resource-limited setting. BMC Res Notes 8: 772.

32. Afolabi AO, Oluwasola AO, Akute 00, Akang EEU, Ogundiran TO, et al. (2010) Review of Fine Needle Aspiration Cytology In The Management Of Goitres In Ibadan, Nigeria. Niger J Clin Pract 13(2): 163-166.

33. Burnand KG, Young AE, Lucas J, Rrolands BJ, Scholefield J (2005) The new Aird's companion in surgical studies. $3^{\text {rd }}$ (Edn.), China: Elsevier.

34. Layfield LJ (1996) Fine-needle aspiration of the head and neck. Pathology (Phila) 4(2): 409-438.

35. Ceresini G, Corcione L, Morganti S, Milli B, Bertone L, et al. (2004) Ultrasound-guided fine needle capillary biopsy of thyroid nodules, coupled with on-site cytologic review, improves results. Thyroid 14(5): 385-389. 